14 Legendre-Bazydlo LA, Haverstick DM, Kennedy JLW, Dent JM, Burns DE. Persistent increase in cardiac troponin I in plasma without evidence of cardiac injury. Clin Chem 2010;56:702-5.

15 Bohner J, von Pape KW, Hannes W, Stegmann T. False negative immunoassay results from cardiac troponin I probably due to circulating troponin I autoantibodies. Clin Chem 1996;42:2046-7.

16 Eriksson S, Halenius H, Pulkki K, Hellman J, Petterson K. Negative interference in cardiac troponin I immunoassays by circulating troponin autoantibodies. Clin Chem 2005;51:839-17.

17 Wang H, Bi X, Xu L, Li Y. Negative interference by rheumatoid factor in alpha-fetoprotein chemiluminescent microparticle immunoassay. Ann Clin Biochem 2017;54:55-9.
18 Choy KW, Teng J, Wijeratne N, Tan CY, Doery JCG. Immunoassay interference complicating management of Cushing's disease: the onus is on the clinician and the laboratory. Ann Clin Biochem 2017;54:183-4.

19 Ismail AAA, Walker PL, Barth JH et al. Wrong biochemistry results: two case reports and observational study in 5310 patients on potentially misleading thyroid stimulating hormone and gonadotropins immunoassay results. Clin Chem 2002;48:2023-29.

Address for correspondence: Dr Adel Ismail, Tanglewood, Chevet Lane, Wakefield WF2 6HL, UK. Email: adelaaismail@aol.com

\title{
The UK's multidisciplinary response to an Ebola epidemic
}

\author{
Authors: Sian Reece, ${ }^{A,}$ Colin S Brown, ${ }^{B},{ }^{*}$ Jake Dunning, ${ }^{C}$ Meera A Chand, ${ }^{D}$ Maria C Zambon ${ }^{\mathrm{E}}$ and Michael Jacobs ${ }^{\mathrm{F}}$
}

\begin{abstract}
The West African Ebola virus disease (EVD) epidemic was the largest and most devastating outbreak of EVD the world has ever seen. Its impact was felt far from the shores of Guinea, Liberia and Sierra Leone, with public health systems and clinicians across the globe confronted with an international response both in the affected region and within their own borders. The UK had a prominent role in response efforts, particularly in Sierra Leone. This article highlights how UK academic, health service, military, commercial and public health professionals all played a significant role both at home and abroad.
\end{abstract}

KEYWORDS: Ebola, outbreak, planning, resilience, response, Sierra Leone, UK

\section{Introduction}

The West Africa Ebola virus disease (EVD) epidemic of 2013-16 was an unprecedented, complex and grave humanitarian crisis. It was the largest known outbreak of EVD in history, with over

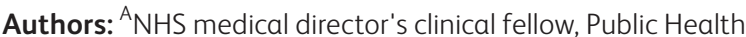

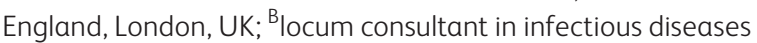
and medical microbiology, Public Health England, London, UK and ex-specialty registrar, University College London Hospitals NHS Foundation Trust, London, UK; ' Consultant in infectious diseases, Public Health England, London, UK and honorary visiting research fellow, Centre for Tropical Medicine and Global Health, University

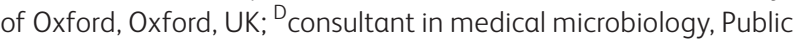
Health England, London, UK and Department of Infectious Diseases, Guy's and St Thomas' NHS Foundation Trust, London, UK; 'E deputy director, National Infectious Service, Public Health England, London, UK; F consultant in infectious diseases, Royal Free London NHS Foundation Trust, London, UK
28,500 clinically compatible cases and 11,000 deaths reported in Guinea, Liberia and Sierra Leone. ${ }^{1}$ The impact on the three most affected countries was immense and had the potential to undo important progress and efforts to rebuild following periods of conflict. Some neighbouring countries were also affected, and many countries outside Africa were required to diagnose and manage EVD cases for the first time.

The first World Health Organization (WHO) public announcement of the EVD outbreak was on 23 March 2014. ${ }^{2}$ This announcement was shortly followed by a call to action from Médecins Sans Frontières, who announced their concerns regarding the lack of international response to the rapidly evolving outbreak. ${ }^{3}$ It has since been widely acknowledged that the international response to this outbreak was too little, too late. ${ }^{4}$ On 8 August 2014, the WHO declared the Ebola outbreak a public health emergency of international concern (PHEIC) ${ }^{5}$

The case fatality rate (CFR) for this epidemic was estimated to be between $31 \%$ and $74 \%$ in the three most affected countries in West Africa, with an average CFR of $48 \%$ for hospitalised patients; this is largely consistent with the range of CFRs reported for previous Ebola Zaire (EBOV) outbreaks. ${ }^{6-11}$ Cases were also diagnosed in Senegal, Nigeria, Mali, USA, UK, Italy and Spain. Evacuated cases were treated in France, Italy, the Netherlands, Switzerland, Norway, Germany, the USA and the UK. Additionally, a more typical, smaller and unrelated EVD outbreak was confirmed in the Democratic Republic of Congo in August 2014.

On 29 March 2016, the WHO declared that the PHEIC had ended. ${ }^{12}$ In the three most affected countries in West Africa, sporadic cases remained a concern despite all countries having been declared free of human-to-human EVD transmission. Small hotspots of EVD continued to occur, with new cases reported as late as April 2016. The complex nature of this outbreak posed significant challenges moving forward, for these countries and for the wider public health community, given 
the possibility of sexual transmission involving survivors and repeated, small clusters of new cases. ${ }^{1,10}$

The UK played a prominent role in the international response, particularly in Sierra Leone. Critical reflection of the events that occurred before, during and after this outbreak are required at both national and international levels, and across all sectors involved in the response. Much of this lookback has been published or is underway. ${ }^{13}$ This article aims to provide a factual account of the significant role UK academic, health service, military, commercial and public health professionals played both at home and abroad. It therefore serves as an uncritical piece from which healthcare professionals can consider their own role in the larger national and international responses of past and future epidemics.

\section{UK response to emerging infections overseas}

Historically, the UK has had a significant presence in responding to emerging and reemerging infections worldwide, be it through international deployment, provision of laboratory capacity, supporting research efforts, or through humanitarian relief and aid. There is a longstanding history of partnerships such as those supported through the Department for International Development (DFID)-funded Trusts Health Partnership Scheme, a scheme managed by the Tropical Health and Education Trust (THET) that aims to link NHS trusts, GP consortiums or academic bodies with overseas partners for bilateral benefit. ${ }^{14}$ THET has over 150 bilateral partnerships registered on their website, and the All-Party Parliamentary Group on Global Health has highlighted the benefits to the UK, including 'health gains for developing countries, leadership development, innovation and international relationships', in addition to providing opportunity for education, shared learning and development at an individual and a national level. ${ }^{15}$ Historically, the UK has contributed to infectious diseases response in areas as diverse as clinical management of trachoma (through Sightsavers), clinical research into tuberculosis/HIV (through the Medical Research Council and Wellcome Trust), programmatic management of malaria (DFID), and neglected tropical diseases (all four agencies). ${ }^{16}$

UK-Med, a branch of the UK International Emergency Trauma Register and the UK International Emergency Medical Register is a Manchester-based organisation aimed at rapidly deploying experts to surgical and medical emergencies. Previously, experts have been sent to post-conflict and crisis settings, such as the Haiti earthquake.

Public Health England (PHE) has a long-standing history of outbreak response through WHO secondments via the Global Outbreak Alert and Response Network (GOARN). In Sierra Leone, PHE was involved in helping to manage a national cholera outbreak 2 years before the EVD epidemic, with subsequent involvement in developing national gastrointestinal laboratory structures. ${ }^{17}$

\section{Ebola - historical context and the West Africa epidemic}

Prior to its recognition in West Africa, EBOV had infected approximately 1,400 people in over ten outbreaks in Central Africa since its discovery in 1976. EBOV is one of four Ebolaviruses capable of causing disease in humans. ${ }^{18}$ EVD is a recognised zoonosis, with fruit bat species the likely natural reservoir. The geographic coverage of EVD extends throughout Central Africa, but a large EVD outbreak was not anticipated on the West African coast although the region is very familiar with viral hemorrhagic fever outbreaks caused by the unrelated Lassa virus; only one previous case of Ebola had been reported. ${ }^{19}$ Case numbers had never exceeded 500 before in an EVD outbreak and never before had EVD affected capital cities. Unexpected, but not unpredictable, the West African epidemic caught the national governments and the world off guard. Existing infection prevention and control (IPC) and treatment guidelines for viral haemorrhagic fevers existed, including for Lassa fever, but had limited application in local clinical settings. ${ }^{20}$ A lack of equipment, consumables, staff numbers and training, and inadequate physical infrastructure hampered early control measures. Water, sanitation and hygiene projects were chronically underfunded. As in many outbreaks, nosocomial EBOV infections were prevalent. Local healthcare workers (HCW) suffered a dual burden of disease as they often cared for relatives or community members at home as well as being exposed in the workplace; HCWs had an overall fiftyfold higher rate of EVD compared with the general public during the epidemic. ${ }^{21}$ The three most affected countries reported 876 confirmed infections and 509 deaths affecting HCWs. ${ }^{1}$ While the infection rate among HCWs was high early in the epidemic, this fell as the epidemic progressed, likely due to improved understanding and implementation of hygiene practices and the availability and correct use of personal protective equipment, along with seeing fewer patients in non-clinical settings. ${ }^{21,22}$

\section{UK military response}

The British military had significant involvement in shaping the UK's Ebola response, working in harmony with efforts coordinated by DFID. The military Ebola Treatment Centre (ETC), co-located with the large Save the Children-run, DFIDfunded site at Kerry Town (a rural village in the Western Area of Sierra Leone approximately 31 kilometres from the national capital Freetown), was the first in-country facility dedicated to treating healthcare professionals, both international and local. This was staffed and supported by waves of nursing, medical and operational staff from both the NHS and military. Royal engineers advised on the construction of DFID-funded and locally-run ETCs, and British troops helped with large scale, WHO-coordinated support to improve IPC measures, assisting in the training of over 4,000 local HCWs. ${ }^{23}$ The Royal Navy ship RFA Argus provided logistical support and offshore treatment for non-EVD injuries, and further support was supplied through transport of medical equipment and supplies to the region. The Western Area, one of the four principle divisions of Sierra Leone that includes the capital city, hosted a command and logistical hub used for operational management early in the epidemic.

\section{The public health response}

The UK's public health response, both national and international, was coordinated by PHE and ensured the provision of public health as well as clinical expertise and advice. The most important measure to curtail the outbreak was to establish measures to control the spread of the disease 
in West Africa, with the aim of removing the threat at source. PHE contributed to these efforts through the provision of experts in epidemiology, infectious diseases, and microbiology and virology to Sierra Leone. PHE also established laboratory capacity within Sierra Leone, where they were the largest provider of field pathology services. Even before PHE laboratories had been established, PHE scientists had joined early deployments of the European Mobile Laboratories (EMLab) to Guinea and Liberia.

The EMLab were designed by the Bundeswehr Institute of Microbiology in Munich, Germany, to improve the laboratory capacity to respond to outbreaks of serious emerging infections in Europe and Africa. Each laboratory can be packaged in 10-15 $30 \mathrm{~kg}$ boxes and transported commercially and utilises class III biosafety cabinets. ${ }^{24}$ In March 2014, GOARN requested assistance from the EMLab in Guéckédou, Guinea. Over the course of the outbreak, thosands of samples were tested across three sites in Guinea. The EMLab also supported the work of the WHO field epidemiology teams through provision of rapid genetic sequencing of positive samples. ${ }^{25}$

In a rapidly evolving outbreak of a pathogen unfamiliar to most, keeping abreast of new developments was essential for providing clear and evidence-based advice. PHE provided tailored advice to a wide variety of individuals and organisations within the UK in order to protect the UK population in the event of an imported case. Local and national exercises were conducted with the support of local health protection teams to exercise this guidance and to ensure reactive systems were fully prepared for any suspected case.

From August 2014, exit screening from affected countries was established to prevent symptomatic individuals from travelling. In October 2014, the decision was made to institute screening for passengers returning from affected areas to the UK at ports of entry, including London Heathrow, London Gatwick, Birmingham and Manchester airports, and London St Pancras station, to offer an additional level of protection to the UK. The process involved a combination of medical assessment of returning passengers and the delivery of advice on what to do should returning passengers develop symptoms at a later date, as well as risk assessment for those returning to work as healthcare professionals. Local area teams were tasked to coordinate extensive tracing to reduce the risk of secondary transmission in the event of individuals having been exposed to known cases. The effectiveness of entry screening in the UK solely in detecting cases (at the point of entry) has been debated, aside from its potential role in information provision. $^{26}$

PHE scaled up its core laboratory services for EVD and increased testing capacity by introducing rapid molecular assays at four sites in the UK, in addition to the pre-existing national reference centre at Porton Down. All of these activities have led to revised Advisory Committee on Dangerous Pathogens guidelines for better management of patients, including more detailed advice on use of laboratory equipment and waste management. ${ }^{27}$

\section{The NHS}

The NHS has seen significant involvement in preparedness and planning at all levels, from national engagement of medical royal colleges ${ }^{28}$ within the UK Government's response $\mathrm{e}^{29}$ to the development of integrated care pathways for management of suspected EVD patients by NHS hospitals and primary care services across the country. In addition, many nursing, medical and microbiology departments took on extra workloads for colleagues who were granted time in West Africa. These activities will leave a legacy of improved risk assessment and management pathways for unwell travellers returning from viral haemorrhagic fever (VHF) endemic areas and also those exposed to future novel and emerging infections.

\section{Non-government organisation involvement}

King's Sierra Leone Partnership (KSLP) is one such THETfunded bilateral partnership and has been based at Freetown since early 2013. KSLP works in partnership with the Ministry of Health and Sanitation, Connaught Hospital (the principle adult tertiary referral hospital) and the University of Sierra Leone College of Medicine and Allied Health Sciences on issues of governance, postgraduate training and health systems improvement. By being located in country at the start of the outbreak, and with an infectious diseases workstream already in existence, KSLP was ideally placed to establish Ebola Holding Units and train local staff in screening, isolation, and testing. By 19 January 2015 the five government medical centres, located in the urban Western Area, that were assisted by KSLP had seen over 2,500 patients, of whom over 1,200 were confirmed EVD positive. $^{30}$

Other British non-governmental organisations (NGOs), such as UK branches of Médecins du Monde and Médecins Sans Frontières, have long-standing experience of emerging or re-emerging infectious disease threats such as HIV/AIDS, Hepatitis C and tuberculosis. Smaller, niche charities, such as Merlin (now encompassed into Save the Children) have provided dedicated outbreak response.

Many other UK NGOs, such as Oxfam and Save the Children, maintained a continued and significant presence during the outbreak and contributed to national surveillance and communications engagement programmes, among others.

\section{Management of cases in the UK}

A total of 20 confirmed EVD cases were medically evacuated from West Africa to the USA and Europe for treatment. A further four cases were diagnosed and treated outside West Africa: two in the USA, one in the UK and one in Italy. In addition, three incidents of local transmission to HCWs occurred outside Africa: one in Spain and two in the USA. ${ }^{31}$

Three EVD cases were treated in the UK: two nurses were medically evacuated from Sierra Leone and one nurse developed symptoms immediately following return from a deployment to Sierra Leone. Following evacuation by the Royal Air Force, they received high-level care in the specialist isolation unit at the Royal Free Hospital (London), which included multidisciplinary input from medical, nursing, pharmacy, intensive care, physiotherapy and nutritional teams. Novel therapeutics were also administered, including monoclonal antibody cocktails (ZMapp, ZMab and MIL77). One UK patient also experienced rare, late recrudescence of disease, manifesting as acute ebolavirus meningoencephalitis; this was treated with 
an experimental small-molecule antiviral agent (GS-5734) and corticosteroids, and the patient recovered. ${ }^{32}$

Individuals who met suspected case criteria underwent clinical assessment at NHS hospitals across the UK. Clinical algorithms and guidelines were made available by PHE to assist UK clinicians with safe assessment and management of suspected cases. PHE's Rare and Imported Pathogen Laboratory screened over 500 samples for EBOV between 2014 and 2015 (compared with 11-48 samples submitted annually prior to the outbreak).

\section{Translational research and development}

There was significant engagement of academic institutions during the epidemic, with an unparalleled development of ethical agreements, trial designs and international collaborations, and the engagement of NGOs in outbreak research. Rapid outbreak research on this scale and in these timeframes had never been seen before. Both vaccines and novel therapeutics have been assessed in trials and UK involvement was at the fore. The University of Oxford collaborated with researchers in Liberia and Sierra Leone to run pragmatic, phase II clinical trials of two potential treatments. Their trial of TKM-130803 was the only trial to reach a pre-defined statistical endpoint. Unfortunately, this was a futility endpoint; a survival benefit could not be demonstrated in recipients of TKM-130803 in this particular study. ${ }^{33}$ The Liverpool School of Tropical Medicine initiated a trial of convalescent plasma with researchers in Sierra Leone, and KSLP and PHE conducted operational research on rapid diagnostic tests.

Vaccine research also benefited from the formation of effective international collaborations. The London School of Hygiene and Tropical Medicine (LSHTM) initiated phase II vaccine trials in West Africa and the University of Oxford led phase I vaccine trials in the UK and elsewhere. ${ }^{34}$ Researchers from LSHTM and PHE also contributed to the successful ring vaccination phase III trial in Guinea. ${ }^{35}$

These studies, though rapid in relation to standard research and development timelines, have highlighted the need for more rapid initiation of studies and advance preparation for future outbreaks. Unfortunately, despite intense efforts, most trials were initiated as the epidemic receded and case numbers were falling dramatically. The high profile, US-led randomised controlled trial of the promising monoclonal antibody cocktail ZMapp failed to meet its recruitment target and was unable to demonstrate a statistically significant survival benefit. ${ }^{36}$

\section{Industry}

There has been unrivalled involvement of pharmaceutical and diagnostics companies in the field, including both the profit and non-profit sectors, alongside NGOs with expertise in outbreak response. Organisations such as Map Action have delineated geographic trends and mapped the outbreak, including case numbers and the location and status of ETCs, to highlight areas of unmet need. Integration of mobile technology allowed Humanitarian OpenStreetMap to map affected areas to help with spatial epidemiology and physical access. Companies such as ClinicalRM helped integrate research operations into convalescent plasma trials. The British Defence Science and Technology Laboratory and
Corgenix developed rapid diagnostic tests that were evaluated successfully in the field. ${ }^{37,38}$ International pharmaceutical companies engaged with UK researchers to enter potential therapeutic agents into clinical trials; this included promising EVD-specific agents and repurposed medicines short-listed by the WHO. Although the availability of potential treatments was limited, pharmaceutical manufacturers also provided agents for compassionate use on a small scale, including patients treated in the UK. Vaccine developers, including the UK pharmaceutical company GlaxoSmithKline, formed collaborations with the US National Institutes of Health and other international partners to vaccinate at-risk HCWs in the region. Aspen Medical, a private healthcare provider, was contracted by the Australian government to provide care in UK-built ETCs.

\section{Discussion}

The EVD epidemic in West Africa was a grave and unprecedented humanitarian crisis. Eventually, it was brought under control by the remarkable, collaborative efforts of national and international agencies and workers. It is vital that we avoid complacency and learn lessons to prevent similar infectious disease outbreaks from causing such devastation in the future.

There is a need for continued research as West Africa recovers from this outbreak, to ensure evidence is captured and we learn all that is possible to prevent and mitigate future outbreaks. Research protocols and vaccine development should be prepared in advance for rapid implementation in future outbreaks, not only for viral haemorrhagic fevers, but also other known (and unknown) high consequence infectious diseases. This should include clinical studies of conventional therapeutics, such as fluid and electrolyte replacement therapy and antibiotics, and not only novel therapeutics and vaccines. Additionally, stakeholders, regulators and governments need to engage in preparedness activities, and ethical issues should be addressed in advance of an outbreak occurring.

There is a need for careful and considered legacy planning to support affected countries in West Africa, as part of the recovery process. The aim should be to help life to return to a state of normality, while legacy-building and strengthening resilience by improving local capacity in affected and at-risk countries. Work continues in the three most affected countries to ensure robust preparedness for the detection, investigation and management of potential cases and the ability to mount an effective, rapid response if required. This work is being conducted alongside efforts to rebuild health and public health programmes and infrastructures to tackle the risk of other communicable and non-communicable diseases in already vulnerable populations. Surveillance systems need to be strengthened, with significant improvements in laboratory infrastructure from local to national level. It has been suggested that the mobilisation of transferable resources utilised for the Ebola outbreak could be used to minimise such a risk. $^{39}$

Domestically, the Science and Technology Committee raised concerns regarding structural weaknesses in relation to human resources and operational procedures for similar events in the future. This includes the UK's capacity to withstand operational disturbances resulting from global health emergencies, and also its ability to develop, assess and manufacture vaccines and medical countermeasures in 
response to a domestic outbreak. The committee suggested there be greater clarity in the government's global health policy and better-defined triggers for a domestic response to disease outbreaks and its capability for overseas deployment. ${ }^{40}$ It was noted that some employers lacked the capacity to release staff who were willing to volunteer or manage their return to work. Some individuals were required to negotiate a leave of absence to volunteer in West Africa. It is recognised that this structural weakness needs to be addressed, for example through the continuation of UK-Med or the support of the WHO's Emerging Diseases Clinical Assessment and Response Network. ${ }^{41}$ Appropriate measures for providing advice to returning travellers will aid roll-out of future services. A High Consequence Infectious Diseases programme was initiated by NHS England in 2014, in collaboration with PHE and the Department of Health. This programme, in part, is a response to lessons learned from EVD and Middle East respiratory syndrome coronavirus incidents in the UK and elsewhere. Additionally, the UK government is funding a Public Health Rapid Support Team (UK PHRST), which will be a partnership between PHE and LSHTM, alongside academic partners King's College London and the University of Oxford. On request, the UK PHRST will support low and middle income countries in investigating a possible or known disease outbreak, with the aim of helping to control a threat before it becomes a national or international health emergency. ${ }^{42}$

The courageous and selfless actions of UK volunteers, alongside the vast numbers of volunteers from the affected countries and other countries around the world, in assisting in the West Africa Ebola outbreak have been recognised and highly commended. ${ }^{34}$ This acknowledges their contribution both to deployment overseas and also in the management of patients and public health preparedness and response efforts in the UK. By November 2014, over 1,000 NHS staff and 185 PHE staff had volunteered their services to the epidemic. The contribution of UK researchers also needs to be recognised. For example, the University of Oxford deployed an international field team of 40 doctors, nurses, pharmacists and scientists to conduct its clinical trials of potential treatments in EVD treatment centres; this was in addition to 14 local HCWs who received training in clinical trials and research staff who contributed from the UK. Significant and important EVD studies have also been conducted by researchers based in the UK, including phase I vaccine trials. Finally, through engaging with NGOs with an in-country presence, such as through KSLP or UK-Med's partnership with GOAL or Save The Children, both local and international leadership and development outcomes can be achieved alongside emergency response.

While awaiting a clear national framework for the facilitation of the timely deployment of public health specialists, clinicians and researchers, we should remain focused on maintaining awareness and preparedness for future domestic and international outbreaks of EVD and other high consequence infectious diseases. Engagement in outbreak deployments should be encouraged and facilitated, as should preparedness activities and training before outbreaks happen.

Learning from the lessons of the recent past, both what went well and what still needs to be addressed, will enable an agile response that will protect both the UK and our global population.

\section{Conflicts of interest}

The authors have no conflicts of interest to declare.

\section{References}

1 World Health Organization. Situation report: Ebola virus disease 12 May 2016. Geneva: WHO, 2016. http://apps.who.int/iris/ bitstream/10665/206313/1/ebolasitrep_12may2016_eng.pdf?ua=1 [Accessed 8 May 2017].

2 World Health Organization. Ebola virus disease in Guinea. Geneva: WHO, 2014. www.afro.who.int/en/disease-outbreaks/outbreaknews/4063-ebola-virus-disease-in-guinea.html [Accessed 8 May 2017].

3 Médecins Sans Frontières. Guinea: Ebola epidemic declared, MSF launches emergency response. Paris: MSF, 2014. www.msf.org/article/ guinea-ebola-epidemic-declared-msf-launches-emergency-response [Accessed 8 May 2017].

4 Grépin KA. Analysis - International donations to the Ebola virus outbreak: too little, too late? BMJ 2015;350:h376.

5 World Health Organization. Statement on the 1st meeting of the IHR Emergency Committee on the 2014 Ebola outbreak in West Africa. Geneva: WHO, 2014. www.who.int/mediacentre/news/ statements/2014/ebola-20140808/en/ [Accessed 8 May 2017].

6 Schieffelin JS, Shaffer JG, Goba A. Clinical illness and outcomes in patients with Ebola in Sierra Leone. N Engl J Med 2014;371:2092-100.

7 Kucharski AJ, Edmunds WJ. Case fatality rate for Ebola virus disease in West Africa. Lancet 2014;384:1260.

8 Ebola Response Team WHO. Ebola virus disease in West Africa the first 9 months of the epidemic and forward projections. $N$ Engl J Med 2014;371:1481-95.

9 Barry M, Traoré FA, Sako FB. Ebola outbreak in Conakry, Guinea: epidemiological, clinical, and outcome features. Médecine Mal Infect 2014;44:491-4.

10 Ansumana R, Jacobsen KH, Idris M. Ebola in Freetown Area, Sierra Leone - a case study of 581 patients. N Engl J Med 2014;372:587-8.

11 Deen GF, Knust B, Broutet N. Ebola RNA persistence in semen of Ebola virus disease survivors - preliminary report. $N$ Engl J Med 2015; doi: 10.1056/NEJMoa1511410. [Epub ahead of print]

12 World Health Organization. Statement on the 9th meeting of the IHR Emergency Committee regarding the Ebola outbreak in West Africa. Geneva: WHO, 2016. www.who.int/mediacentre/news/ statements/2016/end-of-ebola-pheic/en/ [Accessed 8 May 2017].

13 UK Parliament Commons Select Committee. Ebola exposed weaknesses in UK's response to disease emergencies. London: UK parliament, 2016. www.parliament.uk/business/committees/committeesa-z/commons-select/science-and-technology-committee/newsparliament-2015/science-in-emergencies-report-published-15-16/ [Accessed 8 May 2017].

14 Tropical Health and Education Trust. Health Partnership Scheme. London: THET, 2015. www.thet.org/health-partnership-scheme [Accessed 8 May 2017].

15 All-Party Parliamentary Group on Global Health. Improving health at home and abroad: how overseas volunteering from the NHS benefits the UK and the world. London: APPG-GH, 2015.

16 All-Party Parliamentary Group on Global Health. The UK's Contribution to health globally: benefiting the country and the world. London: APPG-GH, 2015.

17 Chattaway MA, Kamara A, Rhodes F. Establishing an enteric bacteria reference laboratory in Sierra Leone. J Infect Dev Ctries 2014;8:933-41.

18 Centers for Disease Control and Prevention. Outbreaks chronology: Ebola virus disease. Atlanta: CDC, 2015. Available online at: www. cdc.gov/vhf/ebola/outbreaks/history/chronology.html [Accessed 8 May 2017].

19 Formenty P, Hatz C, Le Guenno B. Human infection due to Ebola virus, subtype Côte d'Ivoire: clinical and biologic presentation. $J$ Infect Dis 1999 Feb;179 (Suppl 1):S48-53. 
20 Centers for Disease Control and Prevention, World Health Organization. Infection control for viral haemorrhagic fevers in the African health care setting. Atlanta: CDC, 1998.

21 Kilmarx PH, Clarke KR, Dietz PM. Ebola virus disease in health care workers - Sierra Leone, 2014. MMWR 2014;63:1168-71.

22 Matanock A, Arwady A, Ayscue P. Ebola virus disease cases among health care workers not working in Ebola treatment units - Liberia, June-August, 2014. MMWR 2014;63:1077-81.

23 British Army. Going home to face Ebola. London: Ministry of Defense, 2015. www.army.mod.uk/news/28056.aspx [Accessed 8 May 2017].

24 World Health Organization. European mobile laboratory supports Ebola response. Geneva: WHO, 2014. www.euro.who.int/en/healthtopics/emergencies/pages/news/news/2014/08/european-mobilelaboratory-supports-ebola-response [Accessed 8 May 2017].

25 European Mobile Laboratory Project. The first EMLab Unit to West Africa terminates diagnostic activities in Guinea. Hamburg: European Mobile Laboratory Project, 2016. www.emlab.eu/newsevents/news-detail/the-first-emlab-unit-to-west-africa-terminatesdiagnostic-activities-in-guinea.html [Accessed 8 May 2017].

26 Mabey D, Flasche S, Edmunds WJ. Airport screening for Ebola. BMJ 2014;349:g6202.

27 Advisory Committee on Dangerous Pathogens. Management of hazard group 4 viral haemorrhagic fevers and similar human infectious diseases of high consequence. London: Department of Health, 2015.

28 The College of Emergency Medicine. Ebola Guidance for Emergency Departments. Best practice guideline. London: The College of Emergency Medicine, 2014.

29 Public Health England. Ebola virus disease: clinical management and guidance. London: PHE, 2015. www.gov.uk/government/collections/ ebola-virus-disease-clinical-management-and-guidance [Accessed 8 May 2017].

30 Johnson O, Youkee D, Brown CS. Ebola holding units at government hospitals in Sierra Leone: evidence for a flexible and effective model for safe isolation, early treatment initiation, hospital safety, and health system functioning. BMJ Global Health 2016; doi: 10.1136/bmjgh-2016-000030. [Epub ahead of print]

31 Uyeki TM, Mehta AK, Davey RT Jr. Clinical management of Ebola virus disease in the United States and Europe. N Engl J Med 2016;374:636-46.

32 Jacobs M, Rodger A, Bell DJ. Late Ebola virus relapse causing meningoencephalitis: a case report. Lancet 2016;388:498-503.

33 Dunning J, Sahr F, Rojek A. Experimental treatment of Ebola virus disease with TKM-130803: a single-arm phase 2 clinical trial. PLoS Med 2016;13:e1001997.
34 UK Collaborative on Development Sciences. The Ebola Research Database. London: UKCDS, 2015. www.ukcds.org.uk/sites/default/ files/content/resources/International\%20Research\%20Funding\%20 for\%20Ebola\%20AG\%2024.2.15.pdf [Accessed 8 May 2017].

35 Henao-Restrepo AM, Camacho A, Longini IM. Efficacy and effectiveness of an rVSV-vectored vaccine in preventing Ebola virus disease: final results from the Guinea ring vaccination, open-label, cluster-randomised trial (Ebola Ça Suffit!). Lancet 2016;389:505-18.

36 Davey TM. PREVAIL II: a randomized controlled trial of ZMapp $^{\mathrm{TM}}$ in acute Ebola virus infection [abstract]. Boston: Conference on Retroviruses and Opportunistic Infections, 22-26 February 2016:Abstract 77LB. www.croiconference.org/sessions/ prevail-ii-randomized-controlled-trial-zmapp $\%$ E2\%84\%A2acute-ebola-virus-infection [Accessed 8 May 2017].

37 Broadhurst MJ, Kelly JD, Miller A. ReEBOV antigen rapid test kit for point-of-care and laboratory-based testing for Ebola virus disease: a field validation study. Lancet 2015;386:867-74.

38 Walker NF, Brown CS, Youkee D. Evaluation of a point-of-care blood test for identification of Ebola virus disease at Ebola holding units, Western Area, Sierra Leone, January to February 2015. EuroSurveill 2015;20:pii $=21073$.

39 Edelstein M, Angelides P, Heymann D. Ebola: the challenging road to recovery. London: Chatham House, 2016. www.chathamhouse.org/ expert/comment/16859\# [Accessed 8 May 2017].

40 House of Commons Science and Technology Committee. Science in emergencies: UK lessons from Ebola. Second report of session 2016-16. London: House of Commons, 2016.

41 World Health Organization. The WHO Emerging Diseases Clinical Assessment and Response Network (EDCARN). Geneva: WHO, 2016. www.who.int/csr/edcarn/en/ [Accessed 8 May 2017].

42 National Institute for Health Research. UK Rapid Response Team: invitation to submit application. London: NIHR, 2015. www.nihr.ac.uk/ about-us/CCF/Rapid\%20response\%20uk\%20comp/UK_RRT_2015_ Invitation_to_Submit_Applicatio_\%20Guidance_v2.0.pdf [Accessed 8 May 2017].

Address for correspondence: Dr Colin Brown, Public Health England, 61 Colindale Avenue, Colindale, London NW9 5EQ, UK. Email: colinbrown@doctors.net.uk 